\title{
Crise do capitalismo, política ultraliberal e a extinção do ministério do esporte
}

\section{RESUMO}

Estamos diante de um cenário distinto das últimas décadas, pois o aprofundamento da crise do capital nos últimos quatro anos impacta no Brasil e na América Latina com força destruidora dos direitos e das soberanias nacionais de forma mais abrupta. $\mathrm{O}$ objetivo deste ensaio teórico é analisar os impactos das políticas ultra-liberais para o Esporte no Brasil. Especialmente no que diz respeito à diminuição do orçamento da União para políticas públicas de Esporte e, como consequência, o fim do Ministério do Esporte. Através de uma perspectiva de análise do orçamento público para políticas do Esporte e de estudos da área que se dedicaram ao tema, pretendese inferir os principais desdobramentos para as políticas de Esporte como direito social e público.

PALAVRAS-CHAVE: Ministério do esporte; Financiamento; Ultraliberalismo
Giovanni Felipe Ernst Frizzo

Doutor em Ciências do Movimento Humano UFRGS

Universidade Federal de Pelotas - UFPel Professor da Escola Superior de Educação Física Departamento de Desportos Pelotas, Rio Grande do Sul, Brasil gfrizzo2@gmail.com (1) https://orcid.org/0000-0002-1825-0097 


\title{
Capitalism crisis, ultraliberal politics and the extinction of the ministry of sports
}

\begin{abstract}
We are facing a different scenario from the last decades, as the deepening of the capital crisis in the last four years has impacted Brazil and Latin America with a force that could destroy social rights and sovereignties more abruptly. The aim of this theoretical essay is to analyze the impacts of ultraliberal policies for sport in Brazil. Especially with regard to the reduction of the Union budget for public sports policies and, as a consequence, the end of the Ministry of Sport. Through a perspective of analysis of the public budget for sports policies and studies of the area that were dedicated to the theme, we intend to infer the main developments for sports policies as social and public law.
\end{abstract}

KEYWORDS: Ministry of Sport; financing; ultraliberalism

\section{Crisis del capitalismo, política ultraliberal y la extinción del ministerio de deportes}

\section{RESUMEN}

Nos enfrentamos a un escenario diferente al de las últimas décadas, ya que la profundización de la crisis del capital en los últimos cuatro años ha impactado a Brasil y América Latina con una fuerza que destruye los derechos y soberanías nacionales de manera más abrupta. El objetivo de este ensayo teórico es analizar los impactos de las políticas ultra liberales para el deporte en Brasil. Especialmente con respecto a la reducción del presupuesto del gobierno para las políticas deportivas públicas y, como consecuencia, el fin del Ministerio de Deporte. A través de una perspectiva de análisis del presupuesto público para políticas deportivas y estudios del área que se dedicaron al tema, pretendemos inferir los principales desarrollos para las políticas deportivas como derecho social y público.

PALABRAS-CLAVE: Ministério de Deportes; Financiación; Ultraliberalismo 


\section{INTRODUÇÃO}

O aprofundamento da crise sistêmica do capitalismo tem se desdobrado em mudanças significativas no padrão de acumulação do capital em todo o mundo. O chamado "assalto ao fundo público" ou, em outras palavras, a destinação de orçamentos estatais para fins privados - tais como o mecanismo das dívidas públicas, privatizações, isenções/renúncias fiscais e cortes orçamentários em políticas sociais - é uma das principais medidas que vêm sendo adotadas por organismos internacionais e governos atrelados à perspectivas de recuperação de taxas de lucro de grandes corporações empresariais.

De forma desigual e combinada, essa caracterização de recuperação da crise têm sido implementada em países como: Estados Unidos (governo Donald Trump), Argentina (governo Maurício Macri), França (governo Emmanuel Macron) e Inglaterra (primeiro-ministro Boris Johnson). No Brasil, a ascensão de Jair Bolsonaro ao governo federal consolidou tal projeto de recuperação da crise à frente do Poder Executivo e a adoção de tais medidas - que aqui caracterizamos como ultra-liberais - têm impactado fortemente na diminuição das políticas públicas para garantia de direitos sociais no país.

Nesse quadro de mudanças nas políticas sociais, circunscreve-se as políticas de acesso ao Esporte no Brasil. Especial destaque para o fim do Ministério do Esporte adotado pelo atual governo e que, a partir de 2019, tornou-se uma secretaria especial do Ministério da Cidadania representando, por um lado, a secundarização da importância do Esporte como um direito social constitucionalmente garantido e, por outro, o enxugamento do Estado para benefício da iniciativa privada como promotora do Esporte.

No caput do artigo no 217 da Constituição Federal de 1988, o esporte aparece como direito do cidadão e dever do Estado, portanto há uma responsabilização da União pela garantia desse direito. Porém, como afirma Athayde et al (2016, p. 40) "os próprios incisos do artigo 217 demonstram um conteúdo híbrido na tentativa de acomodar os interesses públicos e privados ligados ao esporte no interior do texto normativo". E, seguem os autores,

[...] decorridos quase vinte e oito anos de sua promulgação, nos deparamos com um contexto social no qual os direitos sociais (moradia, educação, saúde, cultura, lazer etc) são acometidos por uma visão minimalista de Estado, sufocando o investimento social e impossibilitando o exercício pleno desses direitos (ATHAYDE et al, 2016, p.40). 
Com estes elementos, o objetivo deste ensaio teórico é analisar os impactos das políticas ultra-liberais para o Esporte no Brasil. Especialmente no que diz respeito à diminuição do orçamento da União para políticas públicas de Esporte e, como consequência, o fim do Ministério do Esporte. Através de uma perspectiva de análise do orçamento público para políticas do Esporte e de estudos da área que se dedicaram ao tema, pretende-se inferir os principais desdobramentos para as políticas de Esporte como direito social e público.

\section{ULTRALIBERALISMO E AJUSTE FISCAL NO BRASIL}

De acordo com Fonseca (2005, p. 15) as ideias-chave desenvolvidas pelos intelectuais ultraliberais, podem ser assim tipificadas:

a) precedencia da esfera privada (o indivíduo livre no mercado) sobre a esfera pública, donde os temas da privatização e da desproteção das economias nacionais ocupam papel central;

b) desmontagem do Estado de bem-estar social, pois concebido (e estigmatizado) como ineficaz, perdulário e autoritário, além de indutor de comportamentos que não valorizariam os esforços individuais;

c) forte pressão pela quebra do pacto corporativo entre Capital e Trabalho, em nome da liberdade de "escolha individual" e da "soberania do consumidor";

d) ênfase nas virtudes do livre-mercado por aumentar a riqueza, gerando em consequência uma "natural" distribuição de renda, em razão do aumento da produtividade;

e) aceitação da democracia apenas e tão-somente se possibilitadora do mercado livre e da liberdade individual;

f) ênfase nas mínimas, porém importantes, funções do Estado, que deveriam voltar-se à garantia: a) da ordem e da paz; b) da propriedade privada; c) dos contratos livremente elaborados entre os indivíduos; d) do livre-mercado, através da proibição de práticas anti-concorrenciais; e) da elaboração de "normas gerais e abstratas" de conduta; e f) da desregulamentação de todos os mercados.

Em que pese tais ideias-chave ultra-liberais tenham se tornado a referência dos governos brasileiros desde Fernando Collor (1990-1992), o aprofundamento da crise do capitalismo no Brasil intensificou tal projeto como política de Estado a partir de 2013, quando o país começa a conviver com as políticas de Ajuste Fiscal que, sob a Lei de Responsabilidade Fiscal (BRASIL, 2000) alteradas drasticamente ao longo dos anos, operam-se cortes orçamentários em políticas públicas e direitos sociais, com a justificativa de equilíbrio de receitas e despesas em torno do chamado 
superávit primário que tem como principal objetivo o pagamento de juros e amortizações da dívida pública brasileira. Ou seja, as políticas de Ajuste Fiscal retiram recursos públicos do orçamento da União e o saldo resultante é repassado aos credores da dívida que fomentam o mercado financeiro especulativo.

Na figura abaixo, conseguimos verificar os dados orçamentários da União executados em 2018 que retratam a destinação do maior montante de recursos para o mecanismo da dívida pública.

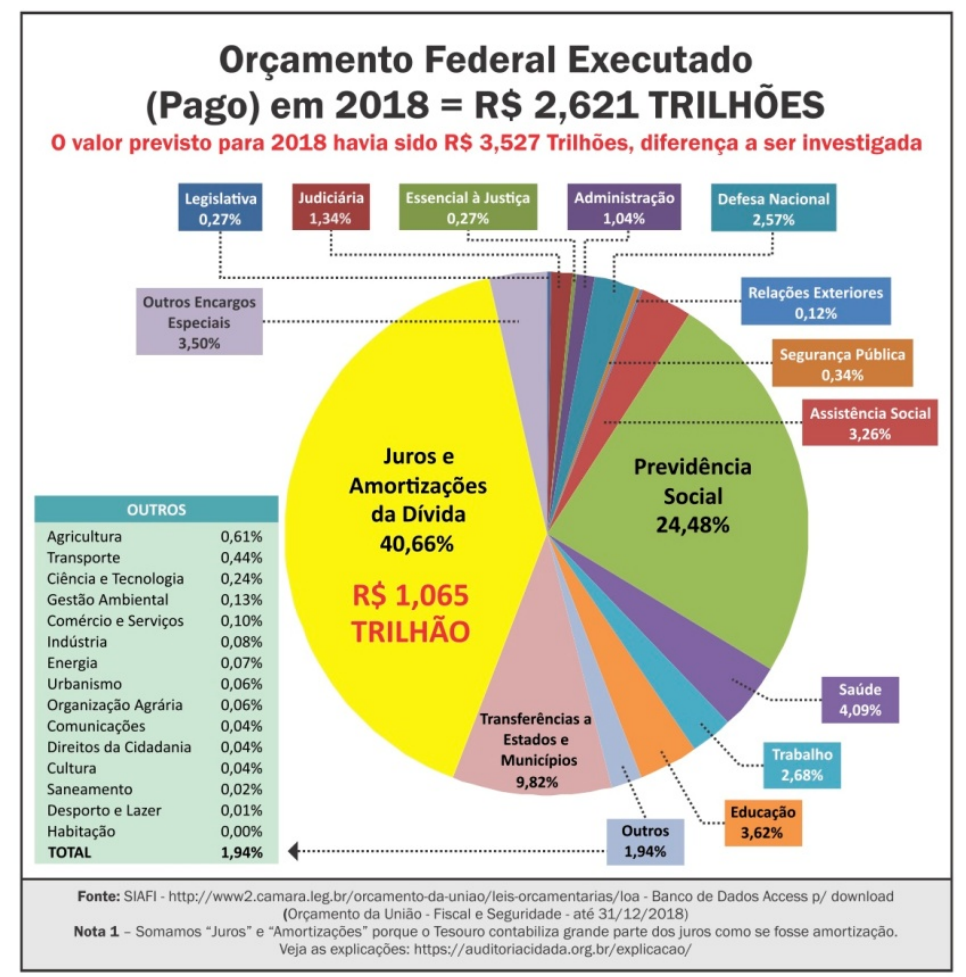

Figura 1 - Orçamento Federal Executado em 2018 Fonte: Auditoria Cidadã da Dívida Pública (2019)

A definição dessa política econômica tem restringido investimentos em direitos sociais como educação, saúde, cultura e esporte. Além da diminuição do orçamento federal para estas políticas públicas, os recorrentes cortes orçamentários dos últimos anos ampliam ainda mais a diminuição de recursos investidos nestas áreas. Enquanto os recursos destinados ao pagamento de juros e amortizações da dívida consomem 40,66\% do orçamento, a educação recebeu 3,62\%, a saúde $4,09 \%$ e o Desporto e Lazer receberam $0,01 \%$ de investimentos. 
Para exemplificar os impactos dessas medidas em direitos sociais, apresentamos um gráfico elaborado pela Associação Nacional dos Dirigentes das Instituições Federais de Ensino Superior (ANDIFES) referente aos repasses do governo federal para as universidades federais.

Figura 2: Repasses do governo às universidade federais

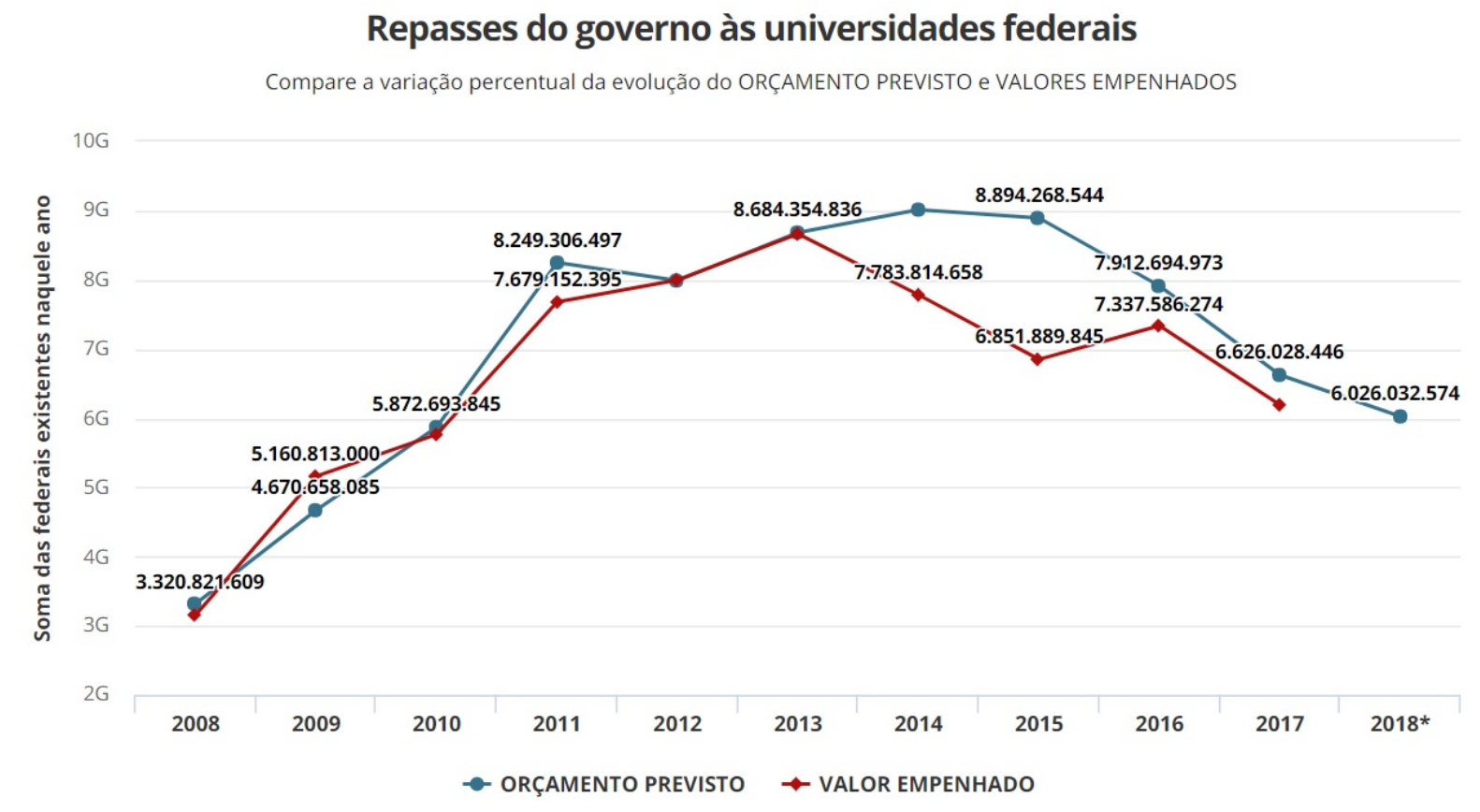

Fonte: Subsecretaria de Planejamento e Orçamento/MEC (*Em 2018, o MEC alterou a metodologia da composição orçamentária e, por isso, parte da verba de investimentos não é mais distribuída na dotação inicial, ou seja, no 'orçamento previsto': ela fica centralizada no MEC e é distribuída ao longo do ano, segundo diversos critérios; por isso, o MEC afirma que a dotação inicial de 2018 de cada universidade não pode mais ser comparada com a dos anos anteriores)

Fonte: ANDIFES (2019)

Neste gráfico, podemos observar uma diferença negativa significativa entre o orçamento previsto e valores empenhados (executado) para as universidades federais a partir de 2014 e, nos anos posteriores, a previsão orçamentária já é negativa em relação ao ano anterior e mantém-se os cortes orçamentários cujos valores executados são ainda menores em relação ao previsto.

O chamado Ajuste Fiscal (também implementados em outros países sob a caracterização de políticas de Austeridade) teve um capítulo importante que demarca o forte desinvestimento em políticas sociais, através da aprovação da Emenda Constitucional (EC) 95/2016 (BRASIL, 2016). Esta modificação legislativa estabeleceu constitucionalmente que todos os investimentos públicos em direitos sociais estarão congelados por 20 anos, ou seja, o orçamento para o ano seguinte estará condicionado ao montante de recursos do ano vigente acrescido de reposição inflacionária e permitindo cortes por conta dos compromissos de superávit da economia. Tendo em vista que as políticas sociais se cumprem praticamente na totalidade pela prestação de serviços públicos e que 
estes sempre tem aumento da demanda por conta situação econômica de crise e aumento da população, na prática, a EC 95/2016 tende a diminuir investimentos para os serviços públicos ocasionando maior precarização dos serviços públicos tanto em esfera federal, como estaduais e municipais.

[...] estima-se que para os próximos 10 anos (2016-2025), somente nas áreas de saúde e educação, deverá ocorrer uma redução dos gastos per capita da ordem de $6 \%$. O fato é ainda mais grave se considerarmos que o ritmo de crescimento populacional, segundo o IBGE, deverá ser de $0,8 \%$ ao ano nesse período, o que significa que mais de 20 milhões de pessoas estarão demandando serviços sociais governamentais (MATTEI, 2019, p. 63).

A perspectiva ultra-liberal de redução do papel do Estado como garantidora de políticas sociais é acompanhada de mecanismos que autorizam a iniciativa privada a ser a principal promotora e responsável pela oferta de serviços que a esfera pública deixa de atender. As diferentes formas de privatizações, desde empresas estatais à prestação de serviços públicos, tem sido recorrentes nos últimos anos, por exemplo, a transferência da gestão de estatais para Organizações Sociais (OS) é a principal forma de atendimento da saúde da população; na educação, o Programa Universidade Para Todos (PROUNI), o Programa Nacional de Acesso ao Ensino Técnico e Emprego (Pronatec) e o Programa de Financiamento Estudantil (FIES) são exemplos de programas que repassam recursos públicos diretamente para as empresas educacionais privadas.

Em relação ao Esporte, Athayde et al (2016, p. 50) afirmam que os Megaeventos Esportivos "recrudesceram interesses ligados ao processo de mercantilização do esporte e exigiram a construção de regras excepcionais para a potencialização de lucros a determinados setores da economia, seja de dentro do esporte, seja de fora desse campo". O assim chamado "legado dos Megaeventos esportivos" repassou grande parte da estrutura esportiva da Copa da FIFA de 2014 e dos Jogos Olímpicos do Rio de Janeiro de 2016, construídas com recursos públicos, para a iniciativa privada na forma de concessão ou venda direta para clubes esportivos ou corporações que exploram economicamente as estruturas.

\section{POLÍTICAS PÚBLICAS E (DES)INVESTIMENTO DO ESPORTE NO BRASIL}

As fontes de financiamento público para o esporte no país podem ser divididas em três formas: orçamentárias, extra-orçamentárias e indiretas. De acordo com Mascarenhas (2006), as fontes orçamentárias tratam dos recursos procedentes de impostos e contribuições sociais do 
orçamento da União, Estados, municípios e Distrito Federal. As fontes extra-orçamentárias se referem aos recursos que não transitam pelo orçamento público e são designados diretamente às entidades esportivas, tais como repasses de loterias, patrocínios e contribuição sobre salários e transferências de atletas. Já as fontes indiretas são compostas por recursos oriundos de desoneração tributária e isenção fisscal, tais como aqueles de patrocínios e doações de pessoas físicas e jurídicas, isenção de impostos na importação de equipamentos esportivos e desonerações de eventos esportivos (CASTRO; MEZZADRI, 2019), como a Lei de Incentivo ao Esporte (BRASIL, 2006) que permite que empresas e pessoas físicas invistam parte do que pagariam de Imposto de Renda em projetos de caráter esportivo.

Assim como, parte das estruturas esportivas que são implementadas em Estados e municípios do país tem recursos oriundos de emendas parlamentares, que são os valores que deputados e senadores federais têm direito para utilização nas localidades nas quais foram eleitos (não obrigatoriamente estes valores são destinados ao esporte). Sobre esta forma de investimento, Teixeira et al (2018) apontaram que entre os anos de 2008 e 2011, 72\% da execução orçamentária do Ministério do Esporte eram oriundos de emendas parlamentares. Os autores mencionam que estas são expressões da pequena política e se vinculam à própria formação do Estado brasileiro, marcada pela utilização dos aparatos de Estado como instrumento de apropriação de poder e acumulação de riqueza pelos setores dirigentes, em que os interesses públicos e coletivos são submetidos aos interesses privados e particulares. Nessa dinâmica, "o clientelismo representa a consolidação desse processo, baseado na troca de favores dentro de uma relação política por apoio, tendo, por exemplo, no voto, uma possível moeda de troca por benesses entre aqueles que detêm o controle do Estado e aqueles que votam” (TEIXEIRA et al, 2018, p. 595).

Castro e Mezzadri (2019, p. 49), apontam que "a institucionalização de fontes públicas para o financiamento do fomento esportivo no Brasil pode ser compreendida como um dos elementos fundamentais para o acesso ao esporte como um direito da população brasileira!’. Porém, os autores chamam a atenção de que

[...] o financiamento público para o esporte na suas diferentes dimensões assegurado pelas dotações orçamentárias e Lei de Incentivo ao Esporte tem se deparado com fragilidades relativas à descontinuidades financeiras, ausência de percentuais mínimos de investimentos, focalização em implantação de infraestrutura esportiva, concentração em regiões e modalidades esportivas específicas (CASTRO; MEZZADRI, 2019, p. 49).

Nos marcos das políticas ultra-liberais de Ajuste Fiscal, em relação ao financiamento do Esporte, além do reduzido orçamento público para a área (conforme apresentado na Figura 1), de 
forma recorrente são anunciados cortes orçamentários que drasticamente diminuem o caráter estatal das políticas de esporte no país. A Lei Orçamentária Anual (LOA) de 2018 foi aprovada com diminuição de 87\% nos recursos para o Esporte comparada ao orçamento de 2017 (FOLHA DE SÃO PAULO, 2017). Já a LOA de 2019 foi aprovada com diminuição de recursos no montante de R\$ 478 milhões em relação ao orçamento de 2018 (UOL, 2018). Nesta política econômica, a preocupação com a democratização do direito ao esporte foi ressignificada e redirecionada em prol dos interesses liberalizantes e de uma visão minimalista de Estado (ATHAYDE et al, 2016, p. 41). Estes autores afirmam ainda, que

\begin{abstract}
Essa transformação foi operada a partir dos instrumentos infraconstitucionais, que se dedicaram a consolidar o processo de mercantilização do esporte, adequando-o às exigências e regras do mercado, bem como fortalecendo a autonomia das entidades de administração e prática esportiva ainda que solidamente amparadas pelo Estado, especialmente no que concerne ao seu financiamento (ATHAYDE et al, 2016, p. 41)
\end{abstract}

Em síntese, as políticas de Ajuste Fiscal de desinvestimento em políticas sociais respaldadas juridicamente pela EC 95/2016, determinam os principais marcos de consolidação da desresponsabilidade do Estado como promotor do Esporte enquanto direito da população, delegando para a iniciativa privada o protagonismo na condução de projetos e programas esportivos que atendem aos interesses de lucro e do Esporte enquanto mercadoria e não como direito.

\title{
O QUE REPRESENTA O FIM DO MINISTÉRIO DO ESPORTE?
}

A utilização do Esporte como instrumento de propaganda política dos governos tem sido significativa na determinação das políticas esportivas encaminhadas pelas instâncias governamentais. Tal utilização é analisada de forma recorrente na literatura científica. Por exemplo, ao analisarmos as relações entre a Federação Internacional de Futebol Associado (FIFA) e os governos ditatoriais latino-americanos, observamos que

Nas ditaduras empresariais-militares da América Latina, nas décadas de 1960 a 1980, a Copa do Mundo de futebol foi utilizada como um mecanismo de propaganda dos regimes militares propalando o suposto desenvolvimento econômico advindos dos regimes ditatoriais que se expressariam nas conquistas esportivas das seleções nacionais (CALHEIROS; BOTH; FRIZZO, 2014, p. 92). 
A título de ilustração, em meio à profunda crise econômica que passa o Brasil, com o intuito de propagandear seu próprio governo, o presidente da república consumiu $\mathrm{R} \$ 201.600$ de recursos públicos para assistir a três partidas da Copa América de Futebol de 2019 (UOL, 2019). Em um país com forte desigualdade social e alta taxa de desemprego de $12 \%$, o valor utilizado para esta propaganda é um montante que o trabalhador ou a trabalhadora que recebem um salário mínimo (atualmente definido em $\mathrm{R} \$ 998$ ) levariam aproximadamente 16 anos ininterruptos de trabalho para receber.

Portanto, para compreender as determinações sociais, políticas e econômicas que fundamentaram a decisão do atual governo de suplantar o caráter ministerial do Esporte é preciso demarcar que a trajetória institucional da área no Brasil esteve mais atrelada à política econômica estabelecida pelos governos e as elites do que as demandas e necessidades da população em acessar o Esporte como direito. Ao tratar desta relação de Estados e a Educação Física, Bracht (1999, p. 73) aponta que há "exemplos marcantes na história desse tipo de instrumentalização de formas culturais do movimentar-se, como, por exemplo, a ginástica: Jahn e Hitler na Alemanha, Mussolini na Itália e Getúlio Vargas e seu Estado Novo no Brasil’. Em relação ao governo Bolsonaro, tal instrumentalização do Esporte para propaganda governamental pode ser observado, por exemplo, na publicidade da Secretaria Especial do Esporte (subordinada ao Ministério da Cidadania) sobre atletas que participaram dos Jogos Pan-Americanos de Lima em 2019 e que o governo atribuiu as conquistas de atletas ao Projeto Bolsa Atleta que, através de formas precárias e inconstantes de recursos para atletas de alto rendimento com destaque em resultados esportivos. Ou seja, o projeto que é mais divulgado pelo governo se refere a parcos recursos destinados apenas à atletas que podem conquistar medalhas e, com isso, ser utilizado como fonte de propaganda do governo federal.

A trajetória institucional do Esporte, conforme informações da página governamental do Esporte $^{1}$, atrelado ao aparato administrativo do Estado brasileiro surge primeiramente em 1937, quando foi criada a Divisão de Educação Física do Ministério da Educação e Cultura. Era o período do Estado Novo de Getúlio Vargas, com forte caráter repressivo e ditatorial, e predominava o projeto higienista em torno de alusões patrióticas de raça e disciplina que relegaram, também, à Educação Física e o Esporte este caráter.

Em 1970, à esta divisão foi atribuída o caráter de Departamento vinculado ainda ao Ministério da Educação e Cultura até 1978 quando o departamento foi transformado em Secretaria de Educação Física e Desporto até 1989. Collor de Melo, em 1990, extingue a secretaria ligada ao

\footnotetext{
Informações disponíveis em: www.esporte.gov.br/index.php/cie/52-ministerio-do-esporte/institucional/oministerio/historico.
} 
Ministério da Educação e cria a Secretaria de Desportos da ligado à Presidência da República e, após o impeachment de Collor, o Esporte voltou a ser vinculado ao Ministério da Educação.

Em 1995, o esporte adquire caráter ministerial com a criação do Ministério Extraordinário do Esporte no governo Fernando Henrique Cardoso e, em 1998, é criado o Ministério do Esporte e Turismo. E, em 2003, o presidente Luiz Inácio Lula da Silva cria o Ministério do Esporte com caráter exclusivo da pasta. A partir destes governos, a política de esportes tem uma ampliação de investimentos em programas de esporte e lazer, esporte educacional e esporte de rendimento, tendo a década dos Megaeventos Esportivos a sua principal política, também com forte caráter de propaganda governamental em torno da área. Tais políticas econômicas e sociais são atreladas ao projeto esportivo cujas principais leis são definidas com o intuito de estabelecer o sistema esportivo brasileiro. Neste sistema, tem lugar uma forte relação público-privada em que se destaca o forte apelo aos Megaeventos Esportivos (especialmente os Jogos Pan-Americano de 2007, a Copa da FIFA de 2014 e os Jogos Olímpicos do Rio de Janeiro em 2016), em que predomina o esporte enquanto mercadoria através do chamado "Esporte Espetáculo".

Importante destacar que os Megaeventos Esportivos caracterizam-se por:

[...] sua influência ser em escala mundial (mesmo em competições continentais); subordinar Estados e governos nacionais às entidades esportivas internacionais; seu "legado" atender a interesses determinados da classe dirigente; acirrar a luta de classes, evocando lutas específicas e gerais da classe oprimida; impor determinada perspectiva ideológica reprodutora da hegemonia; estruturar o aparato militar com organismos internacionais (sob a ameaça de terrorismo); realizar transformações infraestruturais profundas nos locais em que são realizados; ter mobilização midiática e audiência em escala planetária; e operar na lógica contratual mercadológica o esporte, sob a forma de direitos de transmissão, patrocínios etc (FRIZZO; CALHEIROS; FILIPPINI, 2014, p.631).

Em janeiro de 2019, com o início do governo Bolsonaro, o Ministério do Esporte foi novamente transformado em Secretaria Especial do Esporte, dentro da estrutura do novo Ministério da Cidadania e, portanto, rebaixando a importância da pasta para o projeto governamental em curso.

Nos marcos das políticas econômicas ultra-liberais do atual governo, este processo não é apenas vinculado à mudanças institucionais, é possível inferir que ao relegar o esporte a um segundo plano do ponto de vista administrativo no aparato estatal, está presente dois movimentos importantes:

a) o "enxugamento" do Estado e o Ajuste Fiscal, que atribui relevância ainda menor ao Esporte enquanto direito social e também a diminuição de investimentos públicos em políticas 
sociais e de esporte, que acabam promovendo maiores restrições de acesso ao direito por parte da grande maioria da população que não é atendida pelas esferas estatais.

b) incentivo à iniciativa privada como promotora de direitos: a partir da consolidação das leis criadas na década dos Megaeventos Esportivos, a política governamental atual estimula a participação privada na promoção de projetos e programas esportivos principalmente baseados no repasse de recursos públicos para empresas privadas (conforme assinalamos em capítulo anterior).

Sobre o primeiro ponto, os efeitos da política de Ajuste Fiscal que retiram recursos de áreas sociais fundamentais para a população brasileira, já foram sentidos pelas políticas de esporte. Os diversos cortes orçamentários do primeiro semestre de 2019 também afetaram a área: em decreto presidencial editado em julho deste ano, Bolsonaro cortou R\$ 1,4 bilhões do orçamento público, sendo R\$ 619 milhões do Ministério da Cidadania ao qual a Secretaria Especial do Esporte está vinculada (BRASIL DE FATO, 2019a).

Assim como, o enxugamento do Estado, próprio das perspectivas neoliberais e ultra-liberais, traz consigo elementos que explicitam a falta de controle social e público sobre a destinação de recursos da União para empresas que realizam convênios e parcerias-público privadas, abrindo precedentes para irregularidades tão presentes na história brasileira quando se trata de relações entre o setor privado e o público. Como exemplo, além de extinguir o Ministério de Esporte, o presidente também assinou decreto que reduziu em mais da metade o número de servidores públicos que atuam na Secretaria Especial do Esporte e que são responsáveis pela fiscalização sobre a execução de projetos com prefeituras, Organizações Não-Governamentais (ONGs) e entidades esportivas, analisando as prestações de contas destes projetos (BRASIL DE FATO, 2019b)

\section{CONSIDERAÇÕES FINAIS}

Estamos diante de um cenário distinto das últimas décadas, pois o aprofundamento da crise do capital nos últimos quatro anos impacta no Brasil e na América Latina com força destruidora dos direitos e das soberanias nacionais de forma mais abrupta. $\mathrm{O}$ novo padrão de acumulação capitalista, originado com a crise mundial, é composto necessariamente de retrocessos civilizatórios que vão desde a esfera econômica produtiva, com o desmonte de direitos trabalhistas, previdenciários e do serviço público, até a esfera dos direitos humanos com medidas de restrições à liberdades, repressão à lutas sociais e fortalecendo as ideias patriarcais racistas, xenofóbicas e homofóbicas como política de Estado. 
Destacamos que este processo tem desdobramentos retrógrados a partir da introdução das chamadas políticas de Ajuste Fiscal em 2013, a EC 95/2016 e o seu aprofundamento com a política econômica ultra-liberal do governo Bolsonaro. Os cortes orçamentários e a redução do Estado como garantidor de políticas sociais, são determinantes para compreender o atual contexto de retrocesso civilizatório, dentre os quais as políticas de financiamento e concepção do Esporte adquirem uma outra qualidade que beneficia a iniciativa privada e desmonta a estrutura administrativa do Esporte no Brasil.

Neste quadro, insere-se o fim do Ministério do Esporte e sua transformação em Secretaria Especial do Esporte atrelada ao Ministério da Cidadania. É importante destacar que uma política pública de estímulo ao Esporte não necessariamente precisa ter um ministério específico para tal fim, porém apresentamos elementos que nos permitem concluir que essa extinção está atrelada à um projeto econômico e social no qual o papel do Esporte é subordinado à interesses empresariais que tem na mercantilização do Esporte a principal marca.

Assim, o Esporte enquanto um direito social à população e com financiamento próprio com vistas à elevação do padrão cultural e esportivo da classe trabalhadora é restringido por conta da subordinação do país aos interesses econômicos e políticos internacionais, relegando o país a uma economia cada vez mais dependente do capitalismo mundial.

\section{REFERÊNCIAS}

ANDIFES. Repasses do MEC para universidades federais chegam ao menor patamar em sete anos. Brasília-DF, 2019. Disponível em: [www.andifes.org.br/repasses-mec-para-universidadesfederais-chegam-ao-menor-patamar-em-sete-anos]. Acesso em: 5 de agosto de 2019.

ATHAYDE, Pedro; CARVALHO, Miguel; MATIAS, Wagner; CARNEIRO, Fernando; SANTOS, Samir. Panorama Sobre a Constitucionalização do Direito ao Esporte no Brasil. Revista

Motrivivência, Florianópolis, V. 28, n 49, dezembro/2016, p 38-53.

AUDITORIA CIDADÃO DA DÍVIDA PÚBLICA. Gráfico do Orçamento Federal Executado (2018). Disponível em: [www.auditoriacidada.org.br]. Acesso em: 14 de agosto de 2019.

BRACHT, Valter. A constituição das teorias pedagógicas da educação física. Cadernos Cedes, ano XIX, no 48, Agosto/99.

BRASIL. Lei de Responsabilidade Fiscal. Lei Complementar n.101, de 4 de maio de 2000. Presidência da República, Brasília-DF, 2000.

BRASIL. Lei de Incentivo ao Esporte. Lei n.11.438, de 29 de dezembro de 2006. Presidência da República, Brasília-DF, 2006 
BRASIL. Emenda Constitucional n.95, de 15 de dezembro de 2016. Presidência da República, Brasília-DF, 2016.

BRASIL DE FATO. Bolsonaro bloqueia quase R\$ 1 bilhão da Educação, Cultura e Esportes. São Paulo, 31 de julho de 2019a. Disponível em: www.brasildefato.com.br/2019/07/31/bolsonarobloqueia-quase-rdollar-1-bi-da-educacao-cultura-e-esportes. Acesso em: 15 de agosto de 2019.

BRASIL DE FATO. Após decisão de Bolsonaro, projetos do Esporte receberão menos fiscalização. São Paulo, 14 de janeiro de 2019b. Disponível em:

www.brasildefato.com.br/2019/01/14/apos-decisao-de-bolsonaro-projetos-do-esporte-receberaomenos-fiscalizacao. Acesso em: 15 de agosto de 2019.

CALHEIROS, Vicente; BOTH, Vilmar; FRIZZO, Giovanni. O Limite Histórico da Estratégia Democrático Popular e a Copa do Mundo de Futebol. Revista Novos Temas, São Paulo, n.10, $1^{\circ}$ semestre de 2014, p. 83-101.

CASTRO, Suelen Barbosa Eiras de; MEZZADRI, Fernando Marinho. Panorama das Principais Fontes de Financiamento Público para o Esporte Brasileiro. Revista Alesde, Curitiba, v. 10, n. 1, p. 33-52, julho 2019.

FOLHA DE SÃO PAULO. Governo corta $87 \%$ do orçamento do Ministério do Esporte para 2018. São Paulo, 19 de setembro de 2017. Disponível em:

www.folha.uol.com.br/esporte/2017/09/1919798-governo-corta-87-do-orcamento-do-ministerio-doesporte-para-2018. Acesso em: 5 de agosto de 2019.

FONSECA, Francisco Cesar Pinto. A Formação da Agenda Ultraliberal no Brasil: o papel da grande imprensa. In: Anais do XXIX ENCONTRO ANUAL DA ANPOCS. Caxambú-MG, 25 a 29 de outubro de 2005. Disponível em: www.anpocs.com/index.php/papers-29-encontro/gt-25/gt1110/3719-ffonseca-a-formacao/file

FRIZZO, Giovanni; CALHEIROS, Vicente; FILIPPINI, Isabella. Copa do Mundo de 2014: a ofensiva do capital e a violação de direitos humanos e sociais no Brasil. Revista Brasileira de Ciências do Esporte, Florianópolis, v. 36, n. 2, supl., p. S603-S616, abr./jun. 2014.

MASCARENHAS, Fernando. O orçamento do esporte: aspectos da atuação estatal de FHC a Dilma. Revista Brasileira de Educação Física e Esporte, São Paulo, v. 30, n. 4, p. 963-80, 2016.

TEIXEIRA, Marcelo Resende; CARNEIRO, Fernando Henrique; MASCARENHAS, Fernando; MATIAS, Wagner Barbosa. Esporte, Fundo Público e Pequena Política: os reveses de um orçamento (r)emendado. Revista Movimento, Porto Alegre, v. 24, n. 2, p. 593-606, abr./jun. de 2018.

MATTEI, Lauro Francisco. Sistema de proteção social brasileiro enquanto instrumento de combate à pobreza. Revista Katálysis, Florianopolis, v. 22, n. 1, p. 57-65, jan./abr. 2019.

UOL. Ministério do Esporte reduz R\$ 478 milhões no orçamento para 2019. São Paulo, 5 de setembro de 2018. Disponível em: [www.maquinadoesporte.uol.com.br/artigo/ministerio-doesporte-reduz-r-478-milhoes-no-orcamento-para-2019_35405]. Acesso em: 5 de agosto de 2019.

Motrivivência, (Florianópolis), v. 31, n. 60, p. 01-15, outubroo/dezembro, 2019. Universidade Federal de Santa Catarina. 
UOL. Bolsonaro gastou R\$ 201.600 para ver três jogos do Brasil na Copa América. São Paulo, 16 de agosto de 2019. Disponível em: noticias.uol.com.br/politica/ultimasnoticias/2019/08/16/bolsonaro-gastou-r-2016-mil-para-ver-tres-jogos-do-brasil-na-copaamerica.htm?fbclid=IwAR3xImUERAChKM7Zyg6TcgisFo4J5b7ugUQhd0maqt65RjWRLyfLNf8 5Nyk. Acesso em: 16 de agosto de 2019.

\section{NOTAS DE AUTOR}

\section{AGRADECIMENTOS}

Inserir os agradecimentos a pessoas que contribuíram com a realização do manuscrito.

\section{CONTRIBUIÇÃO DE AUTORIA}

Não se aplica.

\section{FINANCIAMENTO}

Não se aplica.

\section{CONSENTIMENTO DE USO DE IMAGEM}

Não se aplica

\section{APROVAÇÃO DE COMITÊ DE ÉTICA EM PESQUISA}

Não se aplica.

\section{CONFLITO DE INTERESSES}

Não se aplica.

\section{LICENÇA DE USO}

Os autores cedem à Motrivivência - ISSN 2175-8042 os direitos exclusivos de primeira publicação, com o trabalho simultaneamente licenciado sob a Licença Creative Commons Attribution Non-Comercial ShareAlike (CC BY-NC SA) 4.0 International. Estra licença permite que terceiros remixem, adaptem e criem a partir do trabalho publicado, desde que para fins não comerciais, atribuindo o devido crédito de autoria e publicação inicial neste periódico desde que adotem a mesma licença, compartilhar igual. Os autores têm autorização para assumir contratos adicionais separadamente, para distribuição não exclusiva da versão do trabalho publicada neste periódico (ex.: publicar em repositório institucional, em site pessoal, publicar uma tradução, ou como capítulo de livro), com reconhecimento de autoria e publicação inicial neste periódico, desde que para fins não comerciais e compartilhar com a mesma licença.

\section{PUBLISHER}

Universidade Federal de Santa Catarina. Programa de Pós-Graduação em Educação Física. LaboMídia - Laboratório e Observatório da Mídia Esportiva. Publicado no Portal de Periódicos UFSC. As ideias expressadas neste artigo são de responsabilidade de seus autores, não representando, necessariamente, a opinião dos editores ou da universidade.

\section{EDITORES}

Mauricio Roberto da Silva, Giovani de Lorenzi Pires, Rogério Santos Pereira.

\section{HISTÓRICO}


Recebido em: 05 de Junho de 2019.

Aprovado em: 17 de Setembro de 2019. 